\title{
Unified Active Filter Biquad Structures
}

\author{
Chun-Ming Chang, Bashir M. Al-Hashimi, and J. Neil Ross \\ Electronics Systems Design Group \\ Department of Electronics and Computer Science, \\ University of Southampton, \\ Highfield, Southampton SO17 1BJ, UK \\ E-Mail:cmc01r@ecs.soton.ac.uk
}

\begin{abstract}
This paper presents one new biquad filter model based on nullators, norators, current mirrors and passive R (resistor) and C (capacitor) elements. Two implementations derived from the new biquad filter model by using second generation current-controlled conveyors (CCCIIs) and operational transconductance amplifiers (OTAs) are also proposed. The two biquad implementations are capable of achieving five important filter performance parameters simultaneously and without trade-offs, including universal filtering, minimum components count and independent control of $\omega_{0}$ and $\omega_{0} / \mathrm{Q}$. This is unlike recently reported filter structures which make certain trade-offs that emphasize some parameters at the cost of others. Simulation results are included confirming the theory prediction.
\end{abstract}

\section{Introduction and motivation}

Despite the extensive literature on active filters, there is still a need to develop new filter structures that offer more advantages than existing structures for example in terms of cost, implementation, and operational flexibility. Two active elements that have received considerable attention from the research community over the last two decades in analogue filter design are: second generation current-controlled conveyors (CCCII) [1-4], and operational transconductance amplifiers (OTA) [5-9]. A unified filter biquad the authors believe should exhibit the following five performance parameters simultaneously and without trade-offs, (i) universal filtering (low-pass, 
high-pass, band-pass, notch, and all-pass), (ii) minimum components count (three active elements and two grounded capacitors), (iii) independent $\omega_{0}$ and $\omega_{0} / Q$ tunability, (iv) no need to impose component choice conditions to realize specific filtering functions, and (v) no need to employ additional active elements to provide filter current outputs explicitly.

Examination of the literature on analogue filters shows that no unified filter biquads based on CCCII or OTA has yet been published. Firstly, we consider recently reported CCCII filters that make certain trade-offs with reference to the above five performance parameters. For example, the filter, reported in [4], has features (i), (iii), and (v). Note notch and all-pass responses are obtained by suitable combination of filtering functions. However, the circuit described in [4] does not meet feature (ii) since it employs five CCCII, and three grounded capacitors, and does not meet feature (iv) since it needs the component choice condition: $\mathrm{C}_{1}=\mathrm{C}_{3}$ to obtain all-pass and notch filter functions. A summary of the performance parameters of the filter reported in [4], and some recently reported filters are given in Table.1. As can be seen, none of the filters are capable of achieving the five performance parameters simultaneously.

Table.1 Performance parameters of recently reported CCCII based filters

\begin{tabular}{|c|c|c|c|c|c|}
\hline $\begin{array}{r}\text { Performance } \\
\text { parameter } \\
\text { Prous }\end{array}$ & (i) & (ii) & (iii) & (iv) & (v) \\
\hline Filter [1] & Yes & Yes & Yes & No & No \\
\hline Filter [2] & Yes & Yes & Yes & No & No \\
\hline Filter [3] & Yes & Yes & Yes & Yes & No \\
\hline Filter [4] & Yes & No & Yes & No & Yes \\
\hline
\end{tabular}


Secondly, we consider recently reported OTA based filter biquads that also make trade-offs with respect to the above five features. For example, In [7], the presented current-mode biquad meets features (i) and (v) but not features (ii) (using one floating capacitor), (iii), and (iv) (using one matching condition). A summary of the performance parameters of the filter reported in [7], and some recently reported filters are given in Table.2. As can be seen, none of the filters are capable of achieving the five performance filters simultaneously.

Table.2 Performance parameters of recently reported OTA based filters

\begin{tabular}{|c|c|c|c|c|c|}
\hline $\begin{array}{c}\text { Performance } \\
\text { parameter } \\
\begin{array}{c}\text { Previous } \\
\text { work }\end{array}\end{array}$ & (i) & (ii) & (iii) & (iv) & (v) \\
\hline Filter [5] & Yes & No & No & No & Yes \\
\hline $\begin{array}{c}\text { Filters 4(a) and 5(a) } \\
{[6]}\end{array}$ & Yes & No & Yes & No & Yes \\
\hline Filter [7] & Yes & No & No & No & Yes \\
\hline Filter 4 [8] & Yes & Yes & No & Yes & Yes \\
\hline Filter [9] & Yes & Yes & No & Yes & Yes \\
\hline
\end{tabular}

The motivation of this paper is to develop a new biquad filter model constructed by an active nullor, current mirrors and passive $\mathrm{R}$ and $\mathrm{C}$ elements. Based on this model, two new implementations by using second generation current-controlled conveyors (CCCIIs) and operational transconductance amplifiers (OTAs) are capable of achieving the above mentioned five performance parameters simultaneously and without trade-offs. Such filters are referred to in this paper as unified biquads.

\section{New biquad filter model and its two implementations}

The proposed new biquad filter model is shown in Fig. 2 where a nullor symbol is shown in Fig. 1. A nullor includes a nullator with the characteristic: $\mathrm{I}_{1}=\mathrm{I}_{1},=0 \mathrm{~A}$ and 
$\mathrm{V}_{11},=0 \mathrm{~V}$ at its input port, and a norator with the characteristic: $\mathrm{I}_{2}= \pm \mathrm{I}_{2}$, (The + or sign is consistent with the + or - type of the norator.) $=$ arbitrary and $\mathrm{V}_{22}$, $=$ arbitrary at its output port $[10,11]$. In Fig. 2, the current mirror is used for duplicating the current signal. Circuit analysis yields the following three current transfer functions:

$$
\begin{aligned}
& \frac{I_{B P}}{I_{\text {in }}}=\frac{-s C_{2} G_{1}}{s^{2} C_{1} C_{2}+s C_{2} G_{1}+G_{2} G_{3}} \\
& \frac{I_{N H}}{I_{\text {in }}}=\frac{s^{2} C_{1} C_{2}+G_{2} G_{3}}{s^{2} C_{1} C_{2}+s C_{2} G_{1}+G_{2} G_{3}} \\
& \frac{I_{L P}}{I_{\text {in }}}=\frac{-G_{2} G_{3}}{s^{2} C_{1} C_{2}+s C_{2} G_{1}+G_{2} G_{3}}
\end{aligned}
$$

The above equations show an inverting band-pass at current output $\mathrm{I}_{\mathrm{BP}}$, a notch function at current output $\mathrm{I}_{\mathrm{NH}}$, and an inverting low-pass function at current output $\mathrm{I}_{\mathrm{LP}}$. An all-pass response can be obtained by summing Eqs. (1) and (2), i.e., joining the two output terminals, $\mathrm{I}_{\mathrm{BP}}$ and $\mathrm{I}_{\mathrm{NH}}$, with the following transfer function:

$$
\frac{I_{A P}}{I_{\text {in }}}=\frac{s^{2} C_{1} C_{2}-s C_{2} G_{1}+G_{2} G_{3}}{s^{2} C_{1} C_{2}+s C_{2} G_{1}+G_{2} G_{3}}
$$

Similarly, a high-pass response can be obtained by summing Eqs. (2) and (3), i.e., joining the two output terminals, $\mathrm{I}_{\mathrm{NH}}$ and $\mathrm{I}_{\mathrm{LP}}$, with the following transfer function:

$$
\frac{I_{H P}}{I_{\text {in }}}=\frac{s^{2} C_{1} C_{2}}{s^{2} C_{1} C_{2}+s C_{2} G_{1}+G_{2} G_{3}}
$$

The proposed filter topology enjoys independent $\omega_{\mathrm{o}}$ and $\omega_{\mathrm{o}} / \mathrm{Q}$ tunability as shown:

$$
\begin{aligned}
& \omega_{o}=\sqrt{\frac{G_{2} G_{3}}{C_{1} C_{2}}} \\
& \frac{\omega_{o}}{Q}=\frac{G_{1}}{C_{1}}
\end{aligned}
$$

The parameter $\omega_{0}$ can be changed either by $G_{2}\left(=1 / R_{2}\right)$ or $G_{3}\left(=1 / R_{3}\right)$, without disturbing $Q$, which can be independently varied by $G_{1}\left(=1 / R_{1}\right)$. Note $\omega_{0}$ can also be 
changed by both components $\left(\mathrm{G}_{2}, \mathrm{G}_{3}\right)$ if wider tuning range of $\omega_{0}$ is required, without affecting Q.

Implementation I: A fundamental nullor-R topology is shown in Fig. 3 which is a three-terminal topology. The characteristic of the three-terminal fundamental topology can be derived and presented in the following matrix relationship:

$$
\left[\begin{array}{c}
I_{1} \\
I_{3 \pm} \\
V_{2}
\end{array}\right]=\left[\begin{array}{ccc}
0 & 0 & 0 \\
\pm 1 & 0 & 0 \\
R & 1 & 0
\end{array}\right]\left[\begin{array}{c}
I_{2} \\
V_{1} \\
V_{3}
\end{array}\right]
$$

However, a dual-output second generation current-controlled conveyor (CCCII) is characterised by the following matrix relationship [1-4]:

$$
\left[\begin{array}{l}
I_{y} \\
I_{z \pm} \\
V_{x}
\end{array}\right]=\left[\begin{array}{ccc}
0 & 0 & 0 \\
\pm 1 & 0 & 0 \\
R_{x} & 1 & 0
\end{array}\right]\left[\begin{array}{c}
I_{x} \\
V_{y} \\
V_{z}
\end{array}\right]
$$

where $\mathrm{R}_{\mathrm{x}}$ is the finite input resistance at the X-terminal of the CCCII and is given by $\mathrm{V}_{\mathrm{T}} / 2 \mathrm{I}_{\mathrm{o}}, \mathrm{V}_{\mathrm{T}}$ is the thermal voltage and $\mathrm{I}_{\mathrm{o}}$ is the bias current of the CCCII. The output terminals, $Z \pm$, can be freely chosen as $Z+$ or Z-. Eq. (8) is the same as Eq. (9) provided $\mathrm{R}_{\mathrm{x}}=\mathrm{R}, \mathrm{y}=1, \mathrm{x}=2$, and $\mathrm{z}=3$. A dual-output CCCII has two output terminals, the other of which is realized by using current mirror for duplicating the output current signal such as $\mathrm{I}_{\mathrm{BP}}$ and $\mathrm{I}_{\mathrm{LP}}$ shown in Fig. 2. Therefore, the proposed new biquad filter model can be implemented by using one single-output and two dualoutput CCCIIs. The CCCII-based biquad implementation of the proposed new biquad filter model is shown in Fig. 4. Circuit analysis yields the same current transfer functions and the same $\omega_{0}$ and $\omega_{0} / Q$ as Eqs. (1) to (7) by the replacement of $G_{1}, G_{2}$, and $\mathrm{G}_{3}$ with $\mathrm{G}_{\mathrm{x} 1}, \mathrm{G}_{\mathrm{x} 2}$, and $\mathrm{G}_{\mathrm{x} 3}$. The implemented CCCII-based biquad enjoys the five 
performance parameters simultaneously mentioned in Section I and is called a unified biquad.

Although not included in the paper, it has been shown that the proposed CCCII based biquad (Fig.4) has low sensitivity values: (i) $\pm 1 / 2$, the sensitivities of $\omega_{0}$ for the passive elements $G_{x 2}, G_{x 3}, C_{1}, C_{2}$, and the active current tracking errors $\alpha_{2}, \alpha_{3}$, (ii) 1 , the sensitivities of $\omega_{0} / Q$ for the passive elements $G_{x 1}$ and $C_{1}$, and (iii) 0 , otherwise. Also it has been found that $\omega_{0}$ is affected by the active current tracking errors $\alpha_{2}$ and $\alpha_{3}$, but $\omega_{\mathrm{o}} / \mathrm{Q}$ is not affected by any active current tracking errors of the three CCCIIs unlike the previous works $[1,3]$.

Implementation II: The characteristic of an operational transconductance amplifier (OTA) is shown in the following matrix relationship:

$$
\left[\begin{array}{c}
I_{+} \\
I_{-} \\
I_{\text {out }}
\end{array}\right]=\left[\begin{array}{ccc}
0 & 0 & 0 \\
0 & 0 & 0 \\
G & -G & 0
\end{array}\right]\left[\begin{array}{c}
V_{+} \\
V_{-} \\
V_{\text {out }}
\end{array}\right]
$$

where $I_{+}, I_{-}$, and $I_{\text {out }}$ are the input current flowing into terminal + , the input current flowing into terminal -, and the output current flowing out of the output terminal, respectively. The two equivalent nullor-G topologies of an OTA have been published [12] and shown in Figs. 5(a) and 5(b). It has been proved that a nullator in parallel with a norator is equivalent to a short circuit [11] which is shown in Fig. 6. Therefore, if we let the negative (resp. positive) terminal in Fig. 5(a) (resp. 5(b)) be grounded, shown in Fig. 7(a) (resp. 7(b)), then both of the two nullor-G topologies shown in Figs. 5(a) and 5(b) are going to become the fundamental nullor-R topology shown in Fig. 3, which appears in the new biquad filter model shown in Fig. 2, provided $\mathrm{G}=$ 1/R but with a grounded terminal 2 , and can be realized by a single-input OTA with a grounded ““_“( (resp. “+”) input terminal, shown in Fig. 7(a) (resp. 7(b)). Moreover, the part model bounded by a closed virtual line shown in Fig. 2 is easily proved and 
equivalent to the nullor- $\mathrm{R}_{1}$ or $\mathrm{G}_{1}$ topology shown in Fig. 8 provided $\mathrm{R}_{1}=1 / \mathrm{G}_{1}$. It means that the proposed new biquad filter model can also be implemented by using one single-output and two multiple-output OTAs* (*A multiple-output OTA has multiple output terminals which can be realized by using current mirrors for producing multiple output signals such as $I_{B P}$ and $I_{L P}$ shown in Fig. 2.). The OTAbased biquad implementation of the proposed new biquad filter model is shown in Fig. 9. Circuit analysis yields the same current transfer functions and the same $\omega_{0}$ and $\omega_{\mathrm{o}} / \mathrm{Q}$ as Eqs. (1) to (7). The implemented OTA-based biquad is also a unified biquad enjoying the five performance parameters simultaneously mentioned in Section I.

\section{Simulation results}

To verify the theoretical analysis of the implemented OTA-based biquad shown in Fig. 9, 2 MHz low-pass, band-pass and band-reject filtering responses with Q of 0.707 have been simulated using H-Spice (level-49) with the following supply voltages, bias current, transconductance and capacitors: $\mathrm{V}_{\mathrm{dd}}=5 \mathrm{~V}, \mathrm{~V}_{\mathrm{ss}}=-5 \mathrm{~V}, \mathrm{I}_{\mathrm{b} 1}=161.66 \mu \mathrm{A}$ leading to $\mathrm{G}_{1}=141.42 \mu \mathrm{S}, \mathrm{I}_{\mathrm{b} 2}=\mathrm{I}_{\mathrm{b} 3}=70.88 \mu \mathrm{A}$ leading to $\mathrm{G}_{2}=\mathrm{G}_{3}=100 \mu \mathrm{S}$ and $\mathrm{C}_{1}=\mathrm{C}_{2}=7.96 \mathrm{pF}$. The OTAs were implemented using the CMOS circuit given in [13]. The transistor models were based on typical $0.5 \mu \mathrm{m}$ CMOS process. Fig. 10 shows the simulated low-pass, band-pass and band-reject filtering responses. By keeping the values of $G_{2}\left(=1 / R_{2}\right)$, $\mathrm{G}_{3}\left(=1 / \mathrm{R}_{3}\right), \mathrm{C}_{1}$, and $\mathrm{C}_{2}$, and varying only $\mathrm{G}_{1}\left(=1 / \mathrm{R}_{1}\right)$, we obtain band-pass and bandreject filter signals with different Q's as shown in Figs, 11 and 12, respectively. The simulation values of passive components and their corresponding bias currents are shown in Table 3. 
Table 3. Component values for simulating the implemented OTA-based band-pass and notch filter with $\mathrm{Q}=0.707,2,6$, and 10 .

\begin{tabular}{|c|c|c|c|c|}
\hline elemen & 0.707 & 2 & 6 & 10 \\
\hline $\mathrm{G}_{1}$ & $\begin{array}{c}294 \mu \mathrm{S} \\
\left(\mathrm{I}_{b}=983.5 \mu \mathrm{A}\right)\end{array}$ & $\begin{array}{c}147 \mu \mathrm{S} \\
\left(\mathrm{I}_{b}=230.8 \mu \mathrm{A}\right)\end{array}$ & $\begin{array}{c}49 \mu \mathrm{S} \\
\left(\mathrm{I}_{b}=8.73 \mu \mathrm{A}\right)\end{array}$ & $\begin{array}{c}29.4 \mu \mathrm{S} \\
\left(\mathrm{I}_{b}=4.02 \mu \mathrm{A}\right)\end{array}$ \\
\hline $\mathrm{G}_{2}$ & $\begin{array}{c}294 \mu \mathrm{S} \\
\left(\mathrm{I}_{b}=983.5 \mu \mathrm{A}\right)\end{array}$ & $\begin{array}{c}294 \mu \mathrm{S} \\
\left(\mathrm{I}_{b}=983.5 \mu \mathrm{A}\right)\end{array}$ & $\begin{array}{c}294 \mu \mathrm{S} \\
\left(\mathrm{I}_{b}=983.5 \mu \mathrm{A}\right)\end{array}$ & $\begin{array}{c}294 \mu \mathrm{S} \\
\left(\mathrm{I}_{b}=983.5\right. \\
\mu \mathrm{A})\end{array}$ \\
\hline $\mathrm{G}_{3}$ & $294 \mu \mathrm{S}$ & $294 \mu \mathrm{S}$ & $294 \mu \mathrm{S}$ & $\begin{array}{c}294 \mu \mathrm{S} \\
\left(\mathrm{I}_{b}=983.5\right. \\
\left(\mathrm{I}_{b}=983.5 \mu \mathrm{A}\right)\end{array}$ \\
$\begin{array}{ccc}\left(\mathrm{I}_{b}=983.5 \mu \mathrm{A}\right) \\
\left(\mathrm{I}_{b}=983.5 \mu \mathrm{A}\right)\end{array}$ \\
\hline $\mathrm{C}_{1}$ & $33.08 \mathrm{pF}$ & $46.8 \mathrm{pF}$ & $46.8 \mathrm{pF}$ & $46.8 \mathrm{pF}$ \\
\hline $\mathrm{C}_{2}$ & $66.16 \mathrm{pF}$ & $46.8 \mathrm{pF}$ & $46.8 \mathrm{pF}$ & $46.8 \mathrm{pF}$ \\
\hline
\end{tabular}

The small simulation discrepancy shown in Figs. 10 to 12 depends upon the non-ideal parasitic capacitance and conductance of the OTA. Numerous publications have reported non-ideal effects of OTA-C filters. One of the most recent is [14]. The nonideal effects of the CMOS OTA include [14] (i) frequency dependent transconductance $A_{j}(s)$ which can be reasonably represented as $g_{j}\left(1-s T_{j}\right)$, (ii) input parasitic capacitance $C_{i p j}^{\prime}$, (iii) output parasitic capacitance $C_{o p j}^{\prime}$, (iv) node parasitic capacitance $C_{n p j}^{\prime}$, and (v) output parasitic conductance $G_{o p j}^{\prime}$. Consider the frequency dependent transconductances, the parasitic capacitances, and parasitic conductances in the implemented OTA-based biquad shown in Fig. 9. The non-ideal output current signals $\mathrm{I}_{\mathrm{BP}}$ and $\mathrm{I}_{\mathrm{LP}}$ are given by

$$
\begin{aligned}
& \frac{I_{B P}}{I_{\text {in }}}=\frac{-\left(s C_{2}^{\prime}+G_{2}^{\prime}\right) g_{1}\left(1-s T_{1}\right)}{\Delta} \\
& \frac{I_{L P}}{I_{\text {in }}}=\frac{-g_{2} g_{3}\left(1-s T_{2}\right)\left(1-s T_{3}\right)}{\Delta}
\end{aligned}
$$


where

$\Delta=s^{2} C_{1}^{\prime} C_{2}^{\prime}+s\left(C_{2}^{\prime} G_{1}^{\prime}+C_{1}^{\prime} G_{2}^{\prime}\right)+\left(s C_{2}^{\prime}+G_{2}^{\prime}\right) g_{1}\left(1-s T_{1}\right)+G_{1}^{\prime} G_{2}^{\prime}+g_{2} g_{3}\left(1-s T_{2}\right)\left(1-s T_{3}\right)$

and $C_{1}^{\prime}=C_{1}+C_{n p 1}^{\prime}+C_{i p 1}^{\prime}+C_{i p 3}^{\prime}+C_{o p 1}^{\prime}+C_{o p 2}^{\prime}, C_{2}^{\prime}=C_{2}+C_{n p 2}^{\prime}+C_{o p 3}^{\prime}+C_{i p 2}^{\prime}$,

$G_{1}^{\prime}=G_{o p 1}^{\prime}+G_{o p 2}^{\prime}$, and $G_{2}^{\prime}=G_{o p 3}^{\prime}$.

Eqs. (11) and (12) show that the parasitic capacitance affects the high frequency response and the parasitic conductance affects the low frequency response. Because $1 / \mathrm{T}_{\mathrm{i}}$ corresponds to frequencies located about to the gigahertz range, the higher the operation frequency is the larger the signal distortion. Simulation results also verify this theory prediction.

\section{Concluding remarks}

One new biquad filter model and its two biquad implementations, including their transformation approaches, based upon CCCIIs and OTAs have been presented. The two biquad implementations are capable of achieving five important performance parameters simultaneously and without trade-offs, unlike some recently reported filter circuits [1-9] and those cited therein. They represent an attractive option in applications where size and cost are important since they employ the least number of passive and active components necessary to realise $2^{\text {nd }}$-order filtering function with independent $\omega_{\mathrm{o}}$ and $\omega_{\mathrm{o}} / \mathrm{Q}$ tunability. Furthermore, the two biquad implementations are useful in applications where operational flexibility is required since they provide numerous filtering functions from the same structure, and without imposing component choice conditions. The theoretical analyses of the two biquad implementations have been validated using simulation. 


\section{References}

1 KIRANON, W., KESORN, J., SANGPISIT, W., and MAMPRASERT, N.:

'Electronically tunable multifunctional translinear-C filter and oscillator', Electron. Lett., 1997, 33, (7), pp. 573-574.

2 ABUELMA'ATTI, M., and TASADDUQ, N. A.: 'New current-mode currentcontrolled filters using the current-controlled conveyor', Int. J. Electron., 1998, 85, (4), pp. 483-488.

3 KHAN, I. A., and ZAIDI, M. H.: 'Multifunctional translinear-C current-mode filter', Int. J. Electron., 2000, 87, (9), pp. 1047-1051.

4. MINAEI, S. and TÜRKÖZ, S.: 'New current-mode current-controlled universal filter with single input and three outputs', Int. J. Electron., 2001, 88, (3), pp. 333-337.

5. SUN, Y., and FIDLER, J. K.: "Design of current-mode multiple output OTA and capacitor filters", Int. J. Electron., 1996, 81, (1), pp. 95-99.

6. SUN, Y., and FIDLER, J. K.: "Structure generation of current-mode two integrator loop dual output-OTA grounded capacitor filters", IEEE Trans. Circuits \& Syst.-II, 1996, 43, (9), pp. 659-663.

7. WU, J., and EL-MASRY, E. I.: "Universal voltage- and current-mode OTAs based biquads", Int. J. Electron., 1998, 85, (5), pp. 553-560.

8. CHANG, C. M.: "New multifunction OTA-C biquads", IEEE Trans. Circuits \& Syst-II, 1999, 46, (6), pp. 820-824.

9. CHANG, C. M., and PAI, S. K.: "Universal current-mode OTA-C biquad with the minimum components", IEEE Trans. Circuits \& Syst.-I, 2000, 47, (8), pp. $1235-1238$. 
10. WILSON, B.: 'Recent developments in current conveyors and current-mode circuits', IEE-Proc.-G: Circuits, Devices and Systems, 1990, 137, (2), pp. 63-77.

11. BRUTON, L. T., RC-Active Circuits Theory and Design, Prentice-Hall, USA, 1980.

12. WU, J.: 'Current-mode high-order OTA-C filters', Int. J. Electron., 1994, 76, (6), pp. 1115-1120.

13. SZCZEPANSKI, S., WYSZYNSKI, A., and SCHAUMANN, R.: "Highly linear voltage-controlled CMOS transconductors", IEEE Trans. Circuits Syst., 1993, 40, (4), pp. 258-262.

14. SUN, Y., and FIDLER, J. K.: 'Synthesis and performance analysis of universal minimum component integrator-based IFLF OTA-grounded capacitor filter', IEE Proc.-Circuits, Devices and Syst., 1996, 143, (2), pp. 107-114.
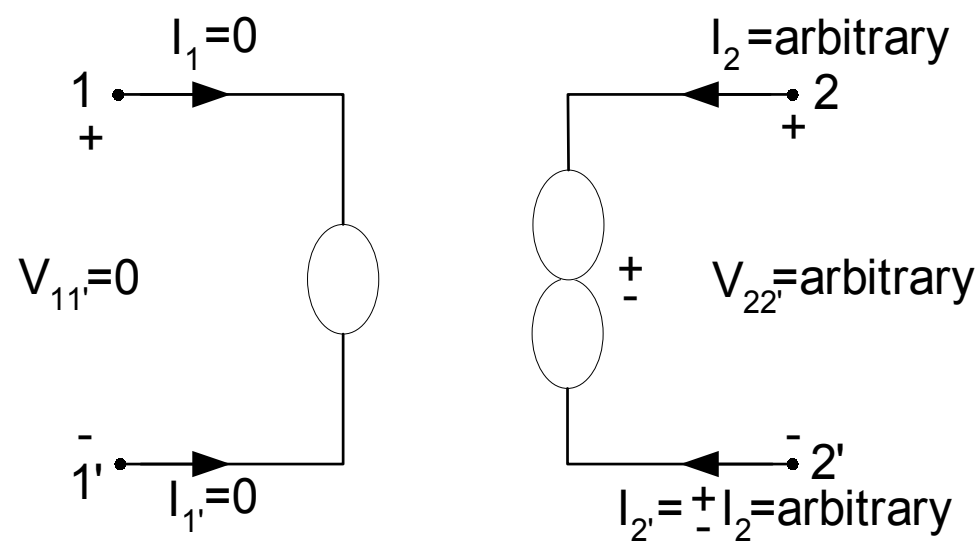

Fig. 1 A nullor symbol with a nullator and a norator 


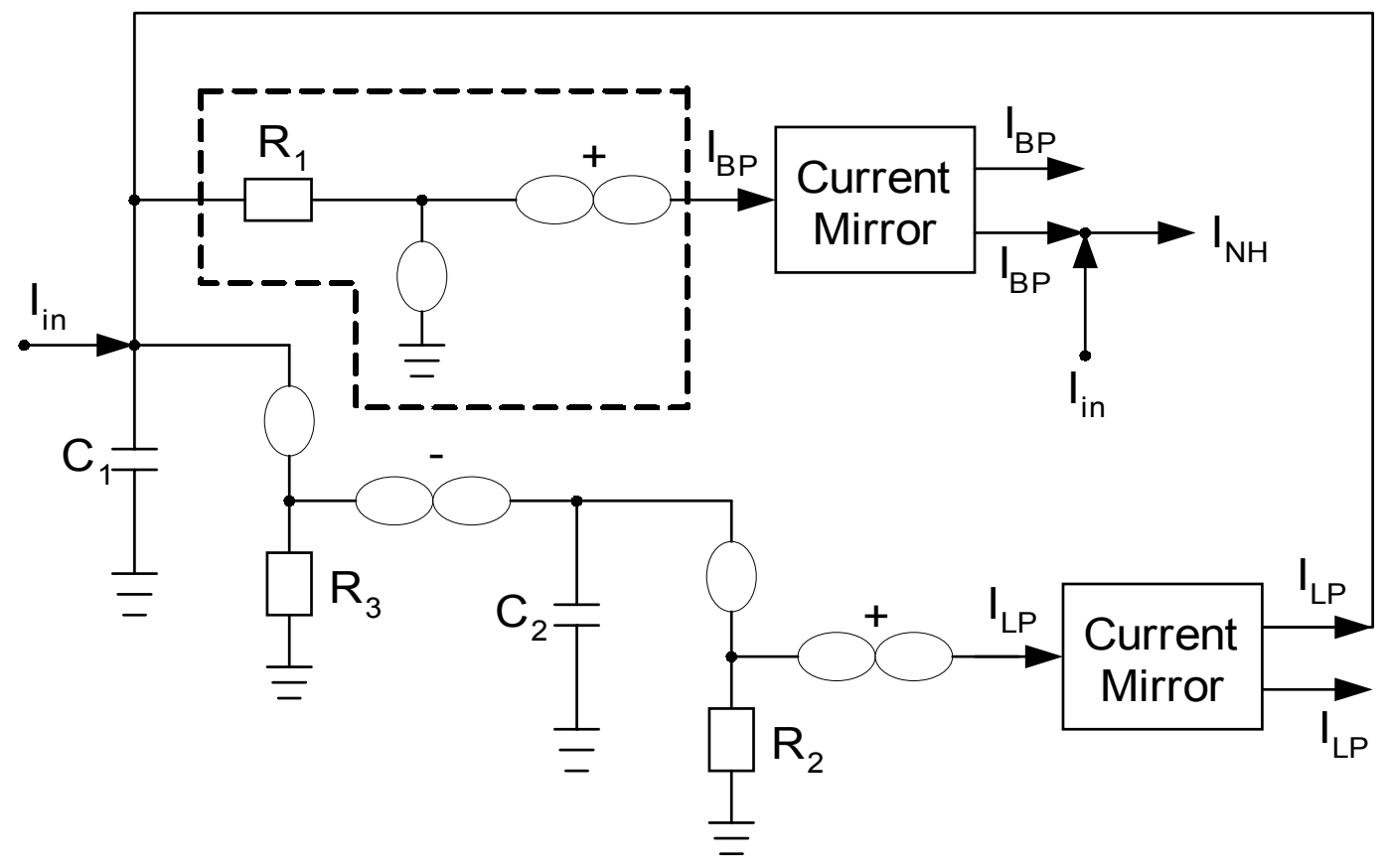

Fig. 2 Proposed new biquad filter model

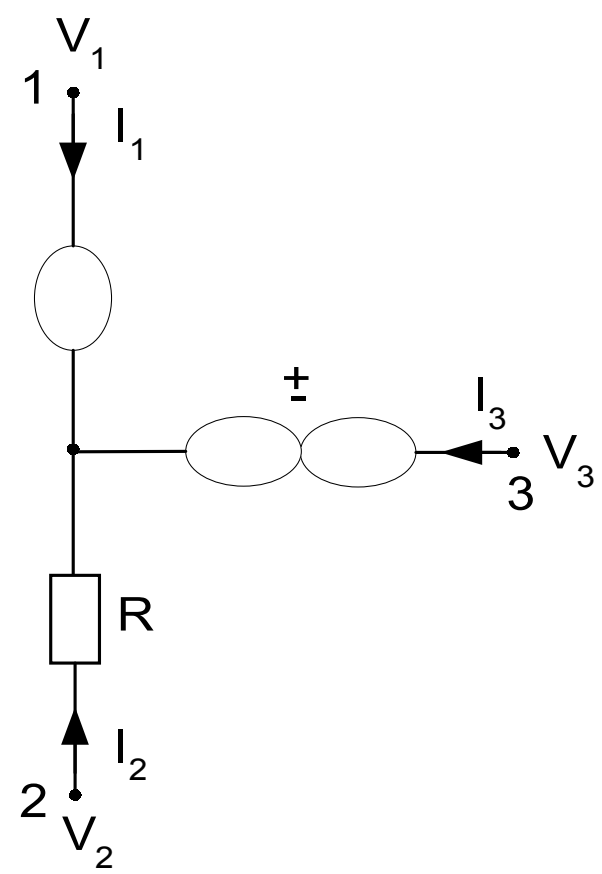

Fig. 3 Fundamental nullor-R topology 


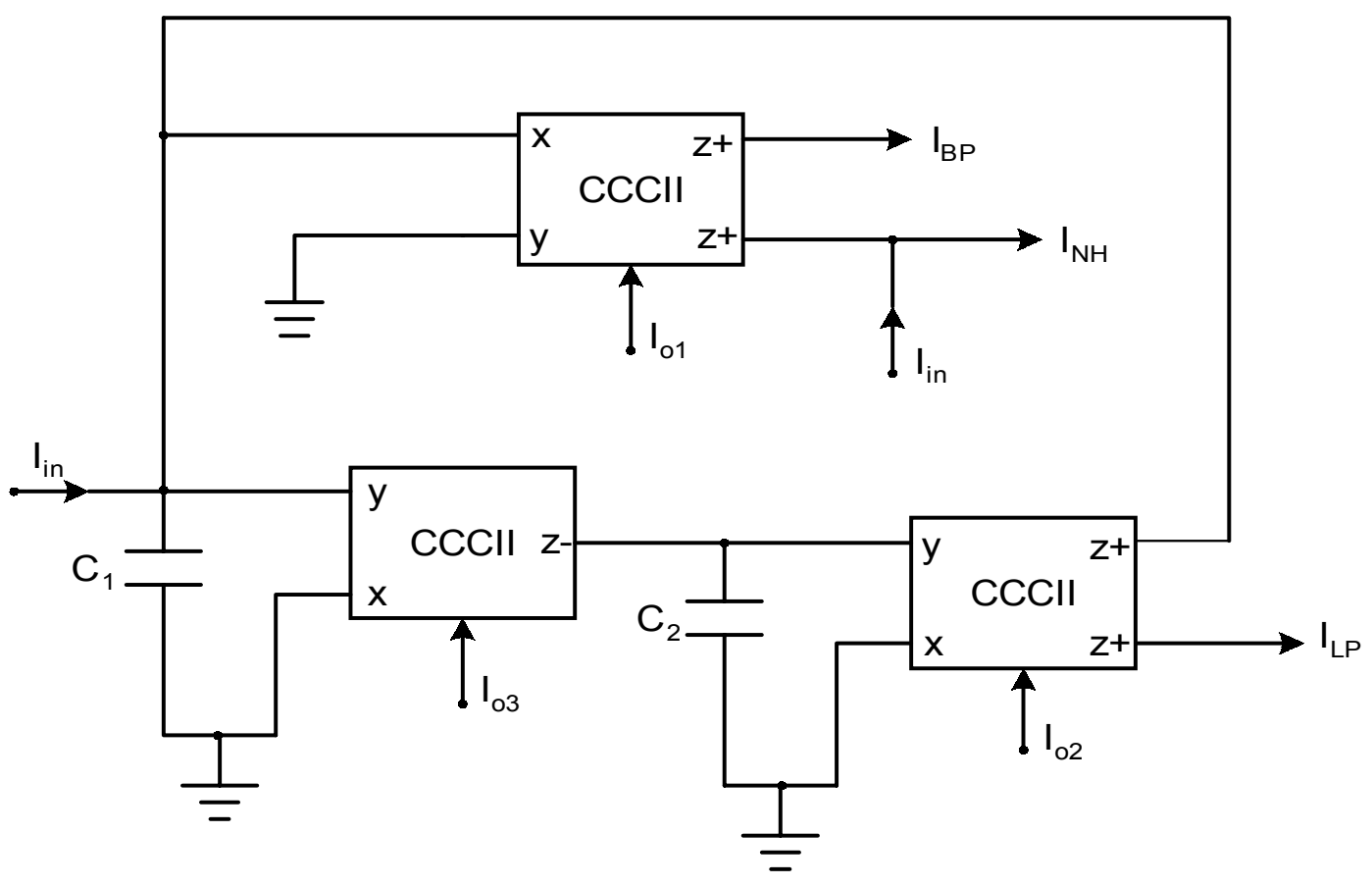

Fig. 4 Implementation derived from the new biquad filter model based on CCCIIs.

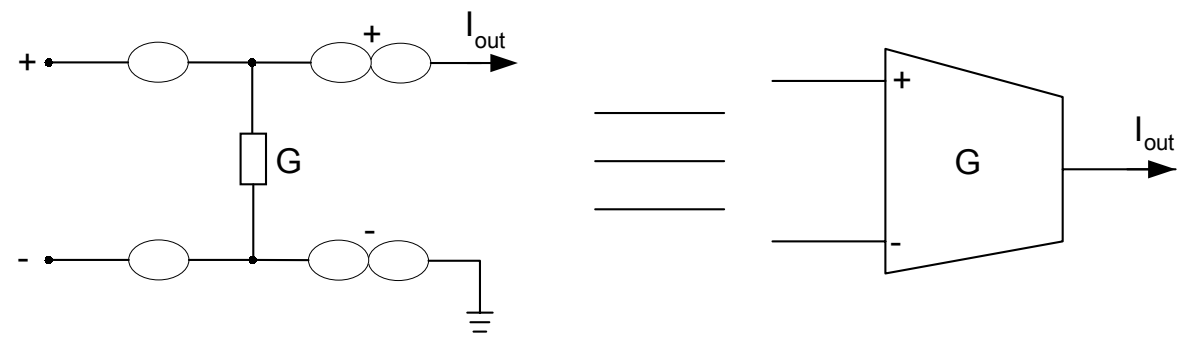

$5(\mathrm{a})$
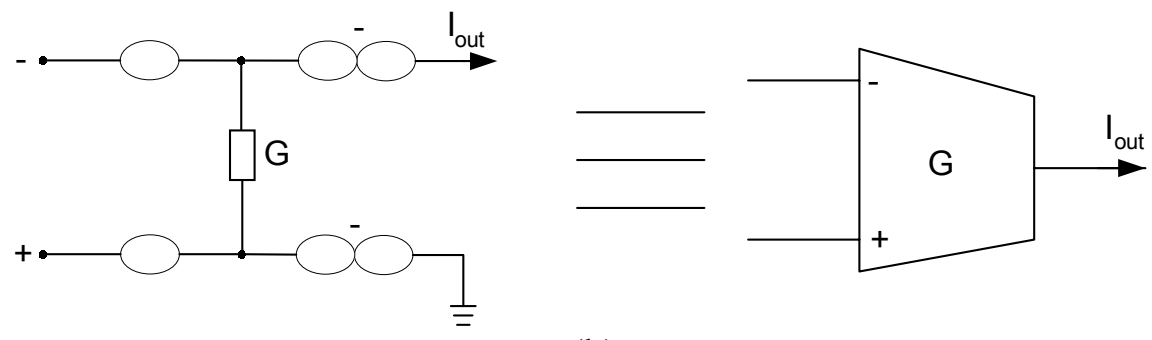

$5(b)$

Fig. 5 Two equivalent nullor-G topologies of an OTA 


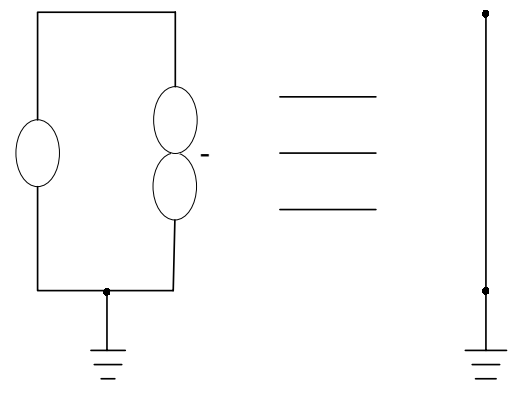

Fig. 6 A nullor equivalence
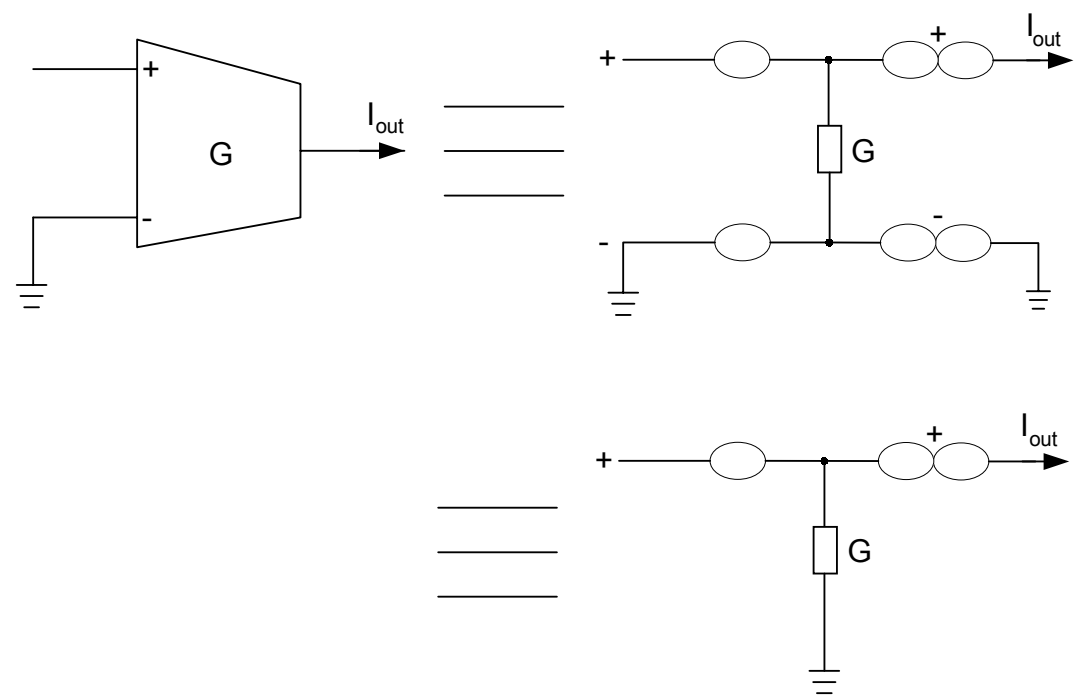

$7(a)$
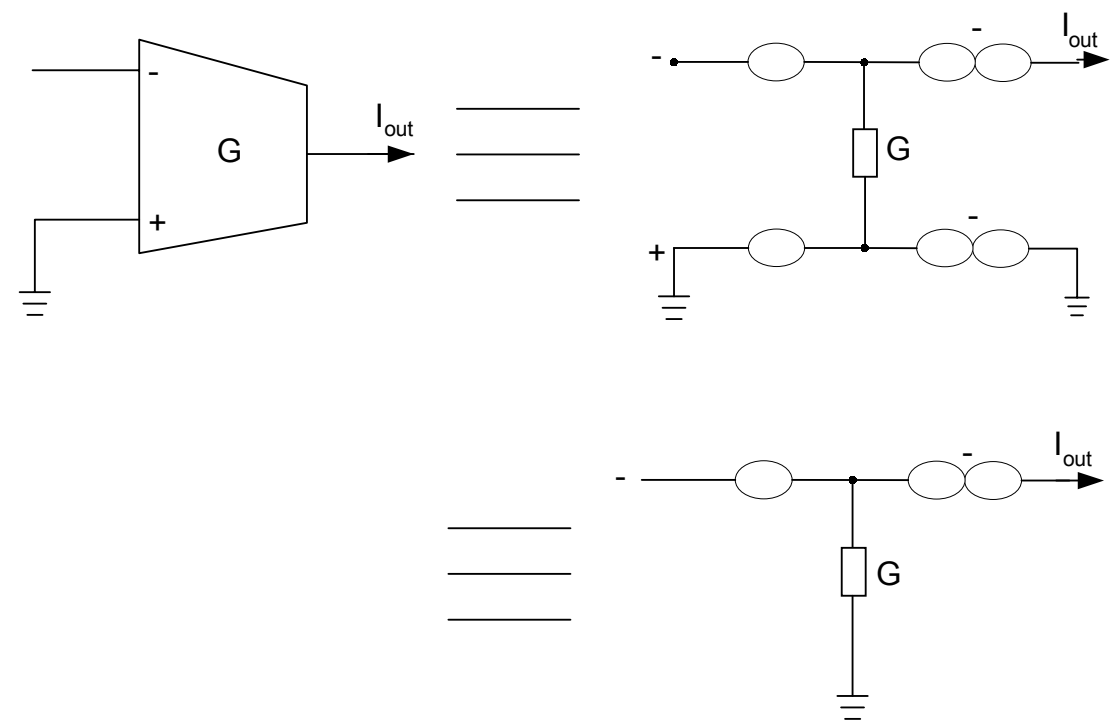

7(b)

Fig. 7 Two equivalent nullor-G topologies of a single-input OTA 

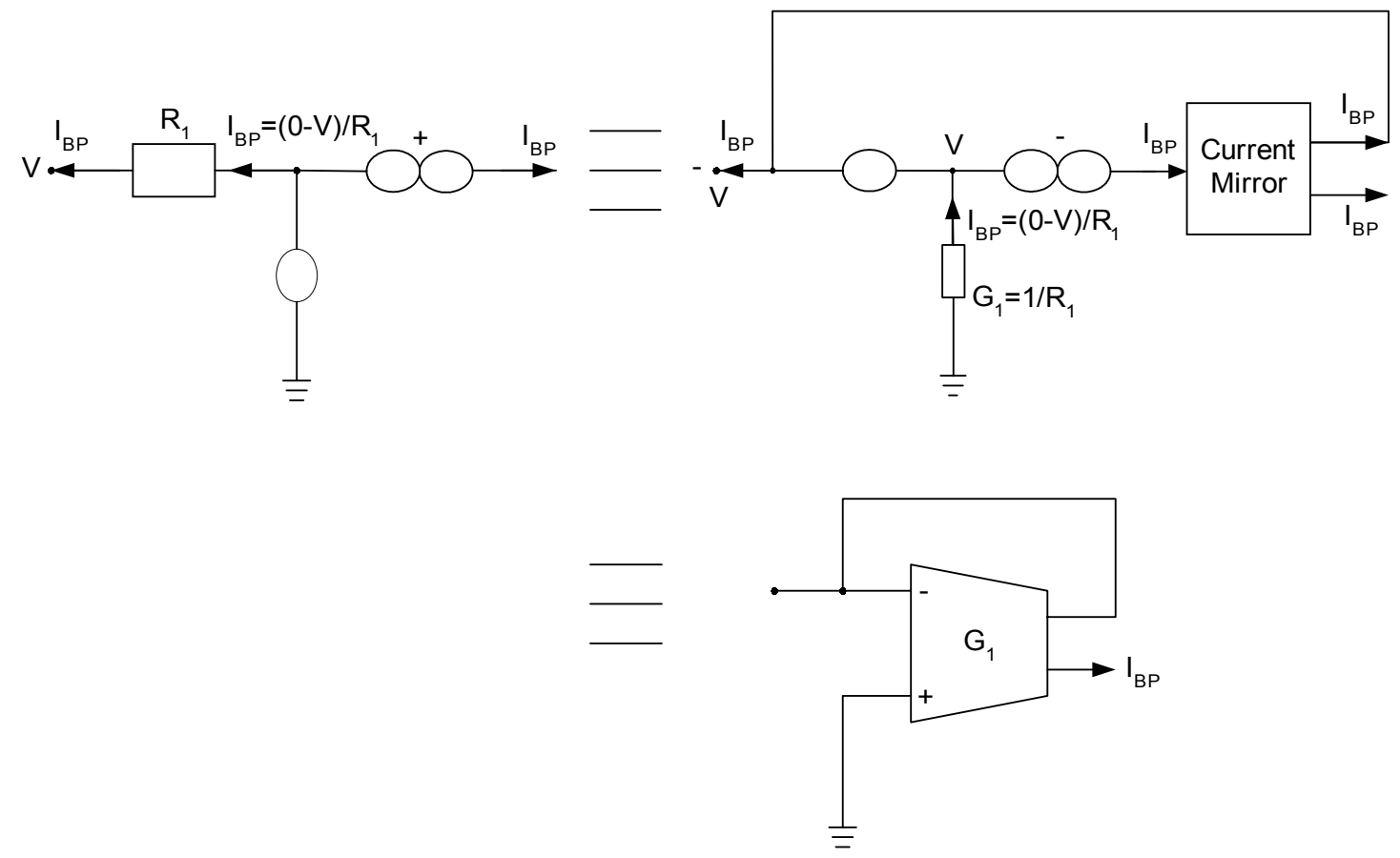

Fig. 8 Two Equivalent nullor- $\mathrm{R}_{1}$ or $\mathrm{G}_{1}$ topologies

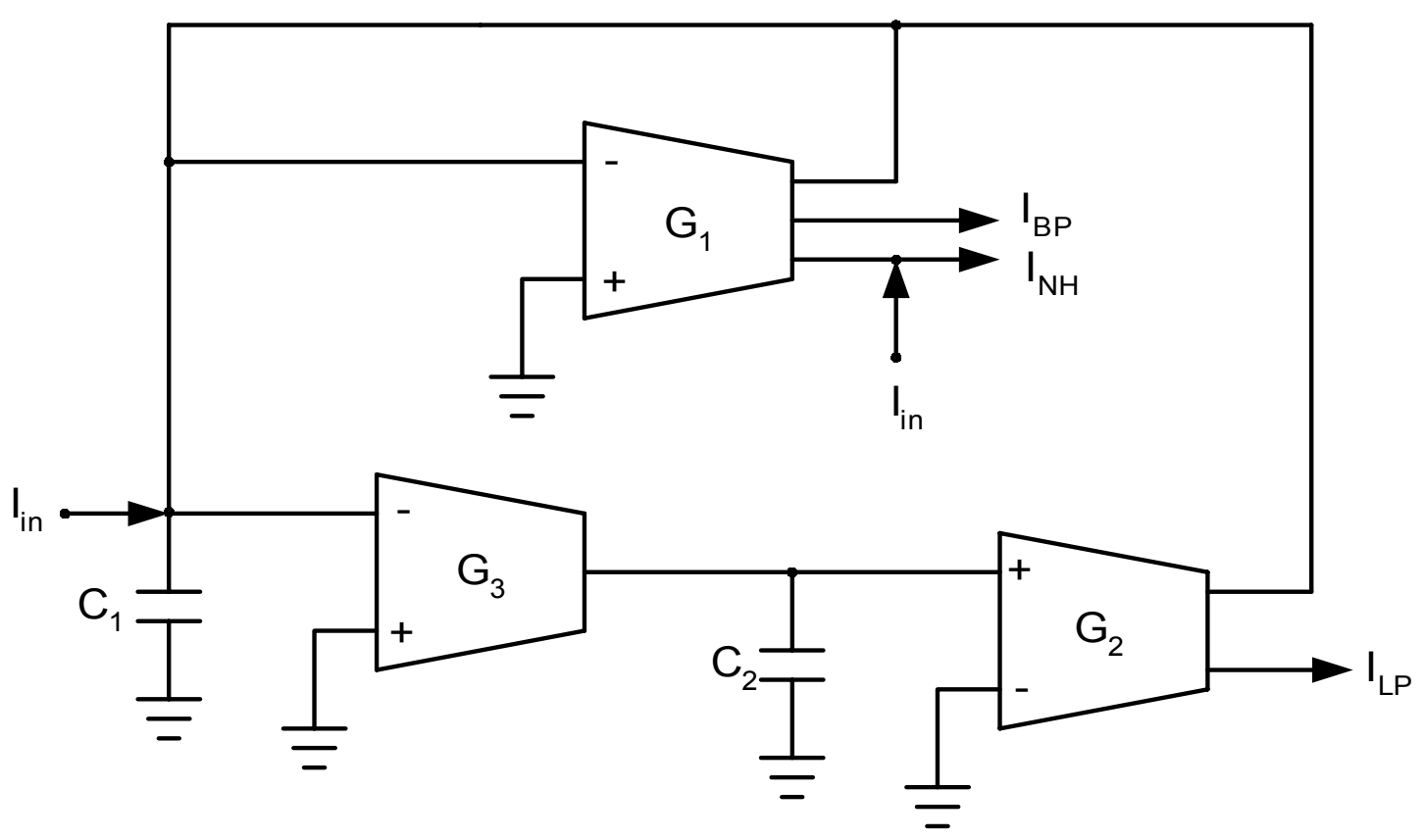

Fig. 9 Implementation derived from the new biquad filter model based on OTAs. 


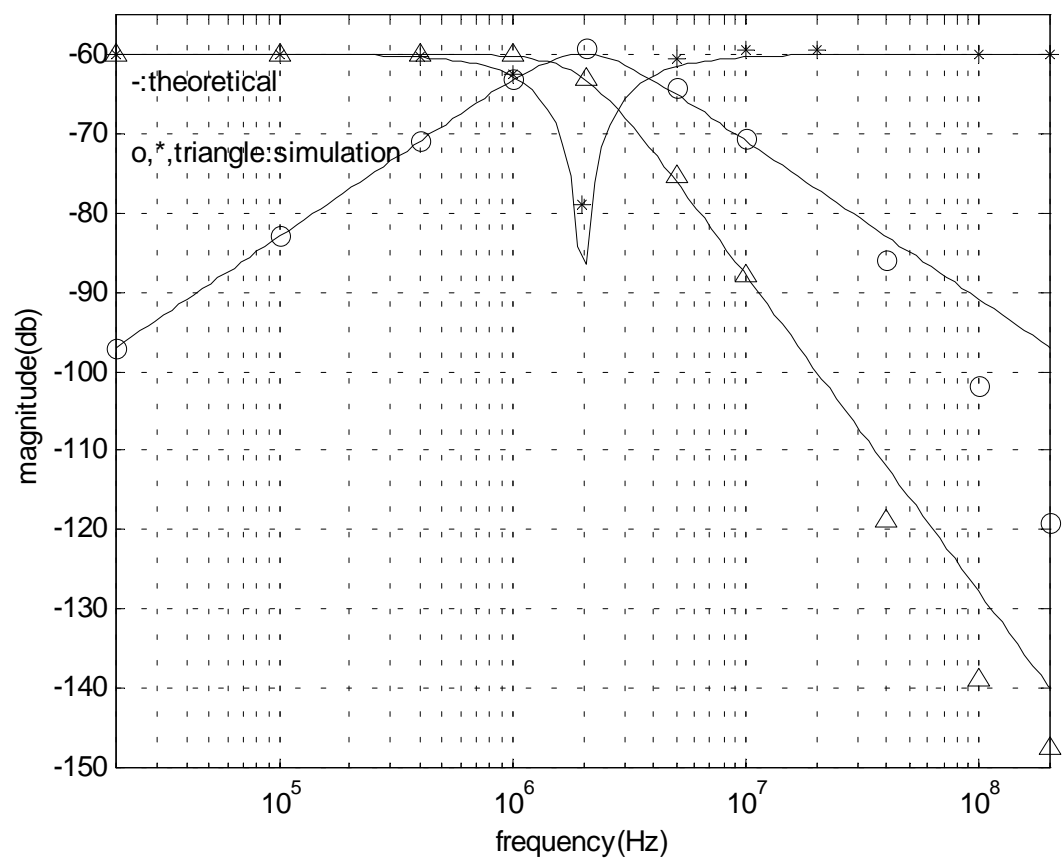

Fig. 10 Simulated frequency responses of low-pass, band-pass, and band-reject output signals of Fig. 9.

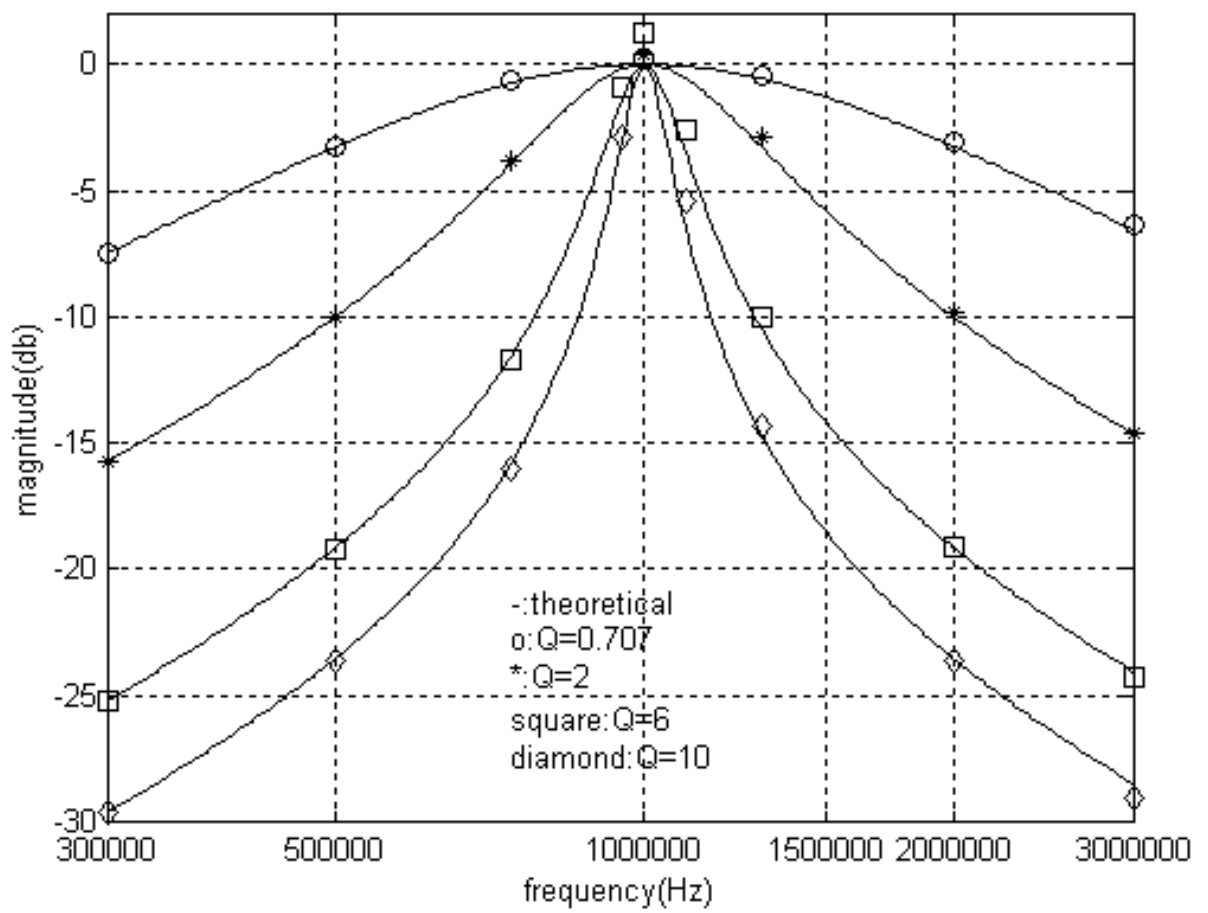

Fig. 11 Simulated frequency responses with $Q=0.707,2,6$, and 10 of band-pass output signal of Fig. 9. 


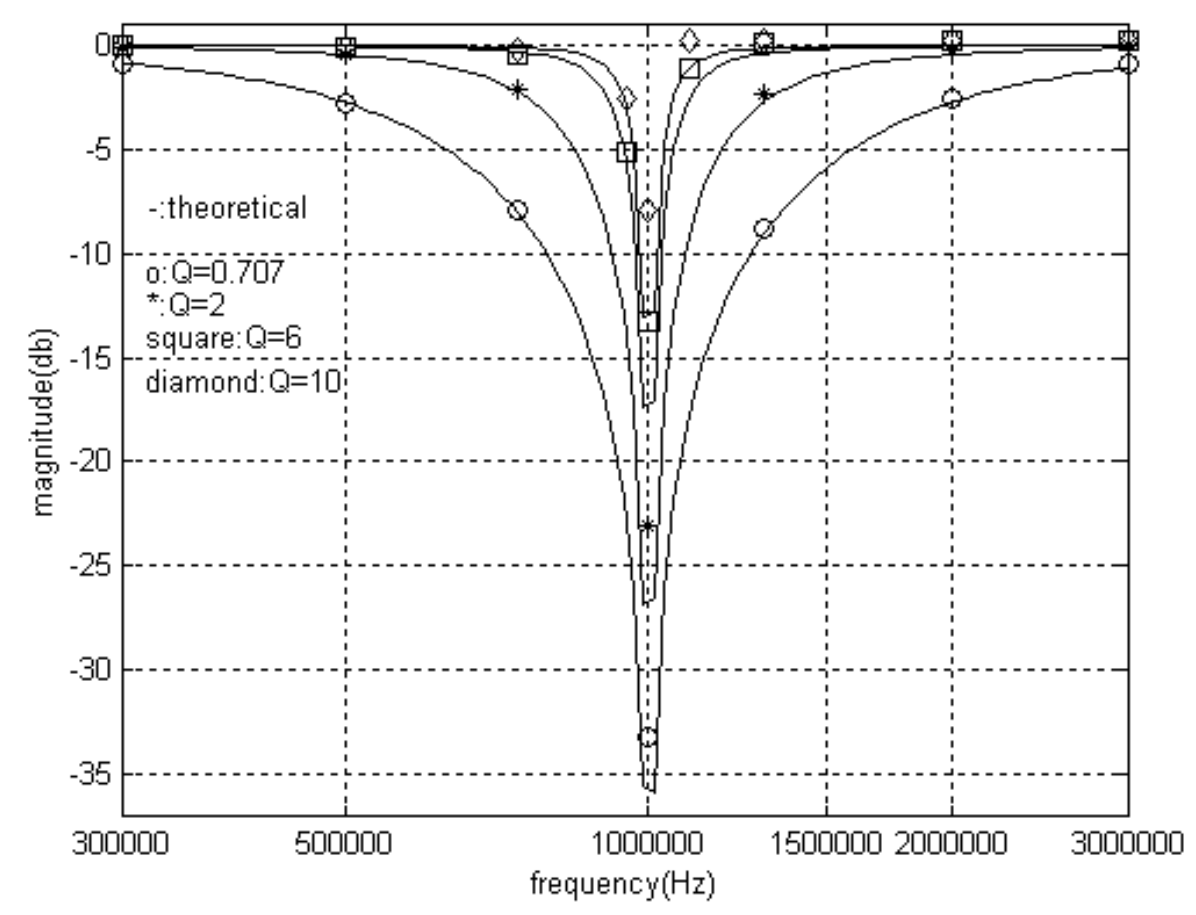

Fig. 12 Simulated frequency responses with $\mathrm{Q}=0.707,2,6$, and 10 of band-reject output signal of Fig. 9. 